\title{
Underrecognized comorbidities of chronic obstructive pulmonary disease
}

\author{
This article was published in the following Dove Press journal: \\ International Journal of COPD \\ 15 July 2015 \\ Number of times this article has been viewed
}

\author{
Joanna Miłkowska- \\ Dymanowska ${ }^{1,2}$ \\ Adam J Białas ${ }^{1,2}$ \\ Anna Zalewska-Janowska ${ }^{3}$ \\ Paweł Górski',2 \\ Wojciech J Piotrowski ${ }^{1,2}$ \\ 'Department of Pneumology and \\ Allergy, Ist Chair of Internal Medicine, \\ ${ }^{2}$ Healthy Aging Research Centre \\ (HARC), ${ }^{3}$ Unit of Psychodermatology, \\ Chair of Clinical Immunology and \\ Microbiology, Medical University \\ of Lodz, Łódź, Poland
}

\begin{abstract}
COPD is associated with different comorbid diseases, and their frequency increases with age. Comorbidities severely impact costs of health care, intensity of symptoms, quality of life and, most importantly, may contribute to life span shortening. Some comorbidities are well acknowledged and established in doctors' awareness. However, both everyday practice and literature searches provide evidence of other, less recognized diseases, which are frequently associated with COPD. We call them underrecognized comorbidities, and the reason why this is so may be related to their relatively low clinical significance, inefficient literature data, or data ambiguity. In this review, we describe rhinosinusitis, skin abnormalities, eye diseases, different endocrinological disorders, and gastroesophageal reflux disease. Possible links to COPD pathogenesis have been discussed, if the data were available.
\end{abstract}

Keywords: COPD, comorbidities, rhinosinusitis, endocrinological disorders, GERD

\section{Introduction}

COPD is a complex, multicomponent disease associated with pulmonary and extrapulmonary manifestations. ${ }^{1,2}$ More than $30 \%$ of patients have one additional chronic disease, and another $40 \%$ have two or more comorbidities. ${ }^{2,3}$ Comorbid diseases prolong hospitalization and are risk factors of short- and long-term unfavorable prognoses. ${ }^{4}$ They are undeniably related to increased health care costs ${ }^{5,6}$ and decreased quality of life. ${ }^{3,7}$ Depression, anxiety, peripheral artery disease, cerebrovascular disease, and symptomatic heart failure have been defined as those concurrent conditions that most severely impact patients health status. ${ }^{8}$ Some COPD-associated diseases are well recognized and are listed in official documents on COPD, such as the Global Initiative for Chronic Obstructive Lung Disease (GOLD). They include: cardiovascular diseases (CVDs) (ischemic heart disease, heart failure, atrial fibrillation, hypertension); osteoporosis (frequently associated with weight loss and sarcopenia); anxiety and depression; lung cancer; infections; metabolic syndrome and diabetes; bronchiectasis; and impaired cognitive function. ${ }^{9}$ Figures 1 and 2 shows the prevalence of different chronic conditions, including underrecognized comorbidities discussed in this paper in patients suffering from COPD, on the basis of the available literature.

The links between COPD and other concomitant diseases are still a subject of debate. In some cases, COPD complications (like hypoxemia/hypercapnia or pulmonary hypertension) may be responsible for certain extrapulmonary symptoms. Comorbidities, like the mere index disease, may represent accelerated aging processes with shared pathological mechanisms, when chronic systemic inflammation and oxidative stress result in telomere dysfunction and DNA damage. ${ }^{10-13}$ Inflammatory local response to inhaled particles and gases (mostly tobacco smoking) may spread out of the respiratory tract (the "spill-over" theory) or, alternatively, one common
Correspondence: Wojciech J Piotrowski Department of Pneumology and Allergy, Medical University of Lodz, Kopcińskiego 22, 90-153 Łódź, Poland

Tel +48426787505

Fax $+48426782 \quad$ I29

Email wojciech.piotrowski@umed.lodz.pl 


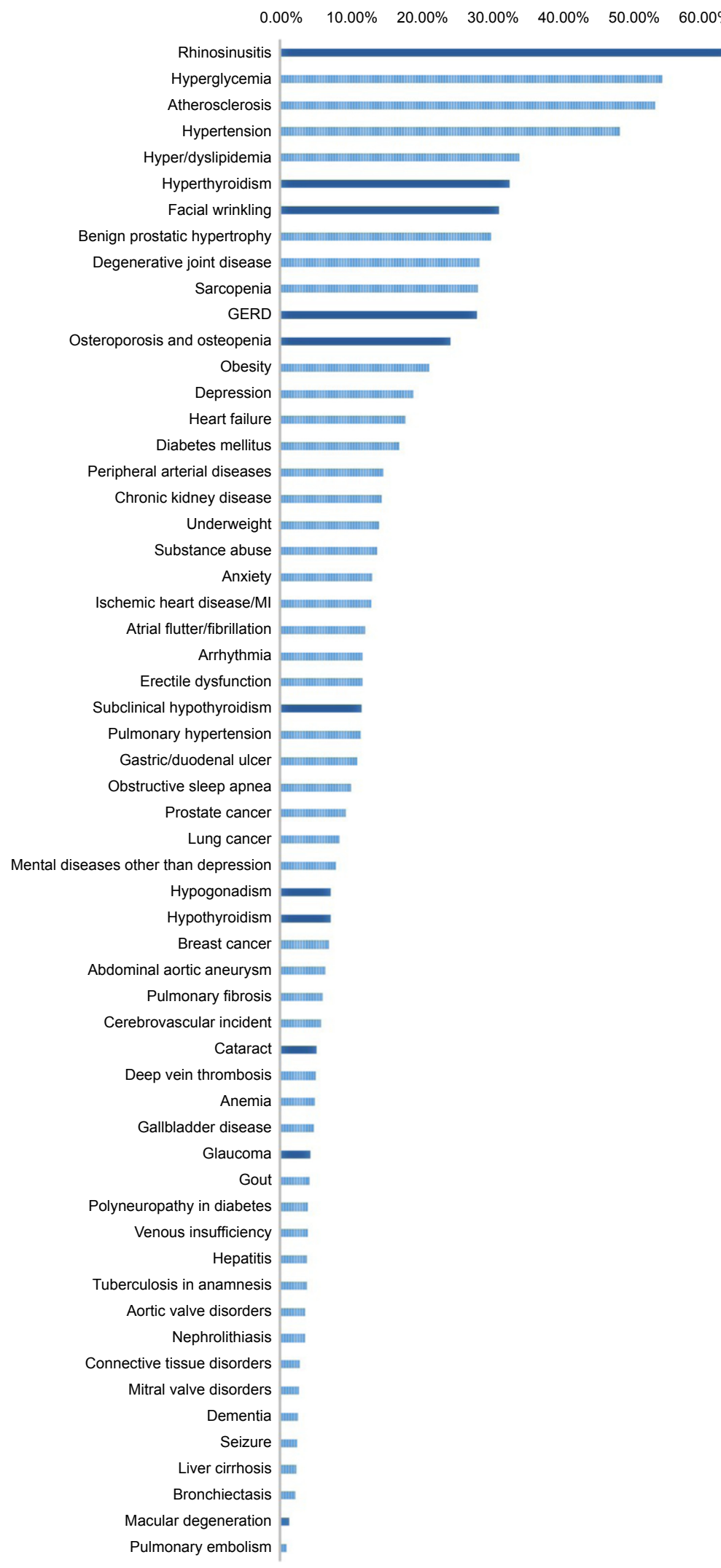

Figure I The prevalence of comorbidities in COPD (prevalence $>2 \%$ ).

Notes: The diseases that are the topic of this study are marked in dark blue. Prevalence was calculated as a weighted average based on the study's sample size. When the data in a manuscript were unclear, the researchers contacted the corresponding author of the manuscript. $8,18,30,31,33,39,52,62,82,83,86,89-91,95-104$ The calculations were performed and the graph was made in Microsoft Excel 20I3.

Abbreviations: GERD, gastroesophageal reflux disease; MI, myocardial infarction. 
trigger (like cigarette smoking) induces systemic inflammation first, and different organ manifestations result from this common root. ${ }^{2,10}$ In COPD, systemic inflammation with chronic low-grade elevation of circulating proinflammatory mediators such as $\mathrm{C}$-reactive protein, fibrinogen, and interleukin (IL)-6 is associated with emphysema, ${ }^{14}$ accelerated disease progression characterized by acute exacerbations, COPD-related hospitalization, and rapid decline of force expiratory volume in 1 second $\left(\mathrm{FEV}_{1}\right) \cdot{ }^{15-17}$ The same markers of systemic inflammation are also associated with aging and comorbid diseases, such as CVD, obesity, and diabetes, and are believed to actively participate in the pathogenesis of these conditions. ${ }^{18-20}$ Of note, according to some studies, not all COPD patients present increased levels of inflammatory mediators in the blood. Garcia-Aymerich et a ${ }^{20}$ identified a "systemic COPD" subtype characterized by increased levels of inflammatory mediators in the blood only in a subgroup of less than one-third of the cohort. These patients were also at greater risk of having obesity, CVD, and diabetes. ${ }^{20}$ Therefore, other mechanisms may be also involved in the pathogenesis of COPD and its comorbidities.

According to García-Olmos et al ${ }^{21}$ COPD most frequently clusters with obesity, osteoporosis, deafness and hearing loss, malignant neoplasms, degenerative joint disease, benign prostatic hypertrophy, generalized atherosclerosis, glaucoma, chronic liver disease, dementia and delusions, chronic skin ulcer, cardiac valve disease, and Parkinson's disease. It is worth noting that some of these diseases are not always recognized by medical professionals as frequent COPD comorbidities.

Several publications, as well as everyday clinical observations, also suggest the frequent coexistence of other conditions and manifestations, as well as involvement of organs other than those defined by GOLD. ${ }^{9}$ These conditions may not be fully recognized either due to their relatively low clinical significance, inefficient literature data, or data ambiguity. Therefore, the aim of this review is to describe and discuss underrecognized extrapulmonary COPD manifestations. The term underrecognized is used in this paper to define diseases that are not listed in the updated edition of GOLD, but for which publications showing such coexistence exist. The list of exclusion and inclusion criteria is provided in Table 1. The diseases that comprise the aforementioned criteria are symptoms from the upper respiratory tract (rhinosinusitis), skin changes and accelerated aging of the skin, eye diseases, endocrine disorders (other than obesity and diabetes), and gastroesophageal reflux disease (GERD). The aim of this review is to discuss the clinical and epidemiological data on the coexistence of these diseases with COPD, as well as
Table I Inclusion and exclusion criteria for underrecognized COPD comorbidities

\begin{tabular}{ll}
\hline Inclusion criteria & I. Coexistent chronic disease \\
& 2. Higher frequency compared to \\
& general population \\
Exclusion criteria & I. Listed in GOLD 20I5 report \\
2. Related to treatment \\
3. Related exclusively to smoking habit \\
4. COPD complications
\end{tabular}

Abbreviation: GOLD, Global Initiative for Chronic Obstructive Lung Disease.

to provide (when possible) an explanation of such frequent coexistence.

\section{Search methodology}

The initial search was conducted using PubMed with the subject headings "chronic obstructive pulmonary disease" (or "COPD") and "comorbidities" (or "comorbidity" or "comorbidities"). Detailed headings in the area of: rhinosinusitis; skin abnormalities; eye diseases; endocrinological disorders; and gastroesophageal disease (GERD) were used. The comorbidities were selected on the basis of inclusion and exclusion criteria, as shown in Table 1. Only English articles with available abstracts were retrieved. For relevant titles, the abstracts were reviewed and, if still relevant, the full version of the article was obtained. References within the selected articles were also reviewed for their relevance. Table 2 shows the number of hits and final selection for each thematic area. The most relevant papers for this selection (showing frequent coexistence of these diseases with COPD), along with the strength of the patients cohorts, are provided in Table 3.

\section{Rhinosinusitis in COPD}

Chronic rhinosinusitis (CRS) may be defined according to the European Position Paper on Rhinosinusitis and Nasal Polyps (EP3OS) by presentation of symptoms and either endoscopic evidence of polyps or radiological evidence by computed tomography (CT). ${ }^{22}$ These criteria may be difficult to fulfill in population-based studies. That is why in the majority of such studies, the definition of CRS is based on the sole symptoms and/or the patient's reported physician-made diagnosis. The symptom-based diagnosis may be biased by several factors, leading to CRS overdiagnosis $;{ }^{23}$ however, in the Global Allergy and Asthma European Network (GA ${ }^{2}$ LEN) study, ${ }^{24}$ in which 57,128 responders from 12 countries were recruited, the value of a postal questionnaire was verified against nasal endoscopy in a subgroup of over 300 patients, and symptombased diagnosis was proved reliable. In this large study, the overall prevalence of CRS in Europe was estimated as 10.9\%, 
Table 2 The process of the PubMed search in selected areas

\begin{tabular}{|c|c|c|c|c|}
\hline Search area & PubMed terms & $\begin{array}{l}\text { PubMed } \\
\text { search }\end{array}$ & $\begin{array}{l}\text { Abstract } \\
\text { selection }\end{array}$ & $\begin{array}{l}\text { The most relevant for the } \\
\text { topic (number of hits) }\end{array}$ \\
\hline \multirow[t]{3}{*}{ Rhinosinusitis } & COPD and rhinosinusitis & 72 & 26 & 20 \\
\hline & COPD and sinusitis & 142 & 52 & \\
\hline & COPD and rhinitis & 202 & 84 & \\
\hline \multirow[t]{3}{*}{ Skin abnormalities } & COPD and skin & 338 & 49 & 15 \\
\hline & COPD and skin pathology & 7I & 49 & \\
\hline & COPD and skin aging & 18 & 15 & \\
\hline \multirow[t]{5}{*}{ Endocrinological disorders } & COPD and endocrinology & 75 & 9 & 17 \\
\hline & COPD and thyroid & 136 & 5 & \\
\hline & COPD and hypogonadism & 37 & 5 & \\
\hline & COPD and adrenal disorders & 66 & 12 & \\
\hline & COPD and parathyroid & 24 & 3 & \\
\hline \multirow[t]{7}{*}{ Eye disorders } & COPD and eye disorders & 251 & 34 & 7 \\
\hline & COPD and eye disease & 299 & 31 & \\
\hline & COPD and glaucoma & 55 & 8 & \\
\hline & COPD and cataract & 49 & 11 & \\
\hline & COPD and myopia & I & I & \\
\hline & COPD and retina & 9 & 4 & \\
\hline & COPD and age-related macular degeneration & 10 & 5 & \\
\hline GERD & COPD and GERD & 194 & 80 & 5 \\
\hline
\end{tabular}

Abbreviation: GERD, gastroesophageal reflux disease.

and it was more common in smokers (odds ratio $[\mathrm{OR}]=1.7$ ). The age group found to be at the highest risk of having CRS was 55-64 years. ${ }^{25} \mathrm{CRS}$ (both with and without nasal polyps) is more frequent in asthma (18\%), atopic dermatitis (7\%), inflammatory bowel disease (3.5\%), autoimmune disorders (up to $5.9 \%$ ), and the frequency of CRS associated with polyps was higher in the first three instances. ${ }^{26}$

The term "common airway disease" is used to describe the frequent coexistence of asthma and upper airway diseases most frequently, allergic and nonallergic rhinosinusitis and nasal polyps. It has been estimated that approximately $90 \%$ of patients suffering from allergic asthma present with signs and symptoms of rhinitis, and about one-third of patients with rhinitis may have asthma. ${ }^{27}$ This well-recognized association led to the formation of theories on the common pathogenesis of these concomitant diseases. ${ }^{28}$

Several authors reported on the higher incidence of CRS in COPD patients..$^{29-33}$ The figures depend mostly on the definition of CRS applied in a study. Upper airway symptom frequency among COPD patients may be as high as $88 \%,{ }^{33}$ but when more objective tests were applied for CRS diagnosis (like CT scans), lower numbers were reported (53\%). ${ }^{31}$ Smoking should be considered the most important risk factor of CRS. Young smokers with normal lung function present

Table 3 List of the most relevant papers per condition

\begin{tabular}{|c|c|c|c|c|c|}
\hline Search area & References & Year & $\begin{array}{l}\text { Number of } \\
\text { patients }\end{array}$ & COPD patients & Prevalence \\
\hline \multirow[t]{3}{*}{ Rhinosinusitis } & Roberts et $\mathrm{al}^{30}$ & 2003 & 61 & 61 & $75.4 \%$ \\
\hline & Piotrowska et $\mathrm{al}^{39}$ & 2010 & 63 & 42 & $97.6 \%$ \\
\hline & Kelemence et $\mathrm{a}^{33}$ & 2011 & 90 & 90 & $53 \%$ \\
\hline Skin abnormalities & Patel et a ${ }^{52}$ & 2006 & 149 & 68 & $31 \%$ \\
\hline \multirow{4}{*}{ Endocrinological disorders } & Laghi et $\mathrm{a}^{82}$ & 2005 & 101 & 101 & $38 \%$ \\
\hline & Mousavi et al ${ }^{83}$ & 2012 & 140 & 140 & $58.6 \%$ \\
\hline & Terzano et al ${ }^{94}$ & 2014 & 155 & 155 & Hyperthyroidism $32.3 \%$ \\
\hline & & & & & Hypothyroidism 21.3\% \\
\hline \multirow[t]{5}{*}{ GERD } & Divo et $\mathrm{a}^{95}$ & 2012 & 1,664 & $\mathrm{I}, 664$ & $17.7 \%$ \\
\hline & Martinez et a ${ }^{86}$ & 2014 & 4,483 & 4,483 & $29 \%$ \\
\hline & Miyazaki et al ${ }^{89}$ & 2014 & 403 & 336 & $34 \%$ \\
\hline & Terada et $\mathrm{a}^{91}$ & 2008 & 122 & 82 & $26.8 \%$ \\
\hline & Ajmera et $\mathrm{al}^{90}$ & 2014 & 2,461 & 2,461 & $29.3 \%$ \\
\hline
\end{tabular}

Abbreviation: GERD, gastroesophageal reflux disease. 


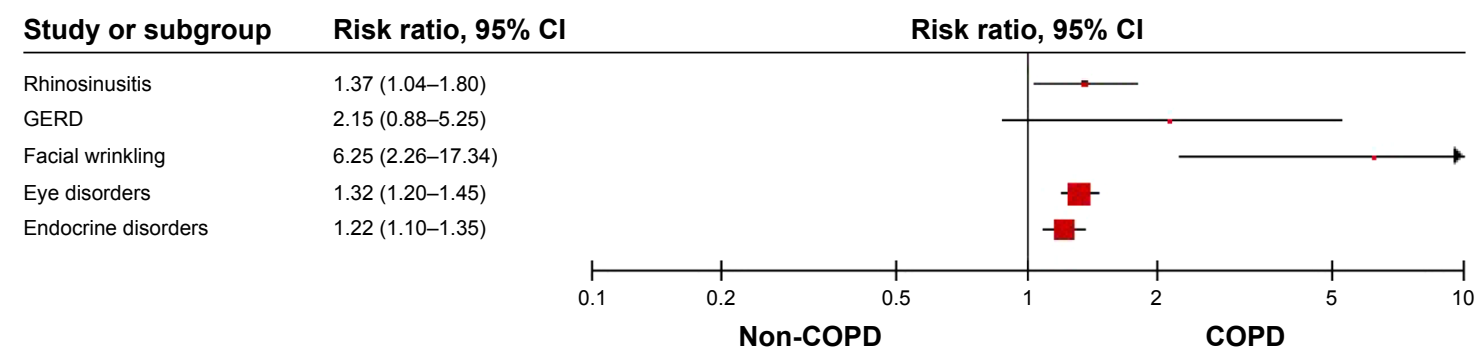

Figure 2 Graph presents the risk ratio with the $95 \% \mathrm{Cl}$ of comorbidities, or groups of comorbidities, that constitute the topic of this study, as based on multiple studies. . $^{39,68,91}$

Note: When risk ratios were not calculated in the study, data were extracted and risk ratios were calculated.

Abbreviations: $\mathrm{Cl}$, confidence interval; GERD, gastroesophageal reflux disease.

with signs of upper airway inflammation, like increased nasal lavage cell number (the cellular pattern composed mainly of macrophages, ciliated, and goblet cells) and increased concentration of myeloperoxidase, suggestive of neutrophil recruitment and activation. ${ }^{34}$ Smoking habit decreases the quality of life related to rhinosinusitis symptoms. ${ }^{35}$ Smokers without evidence of pulmonary pathology also have more pathological changes in their sinus CT scans. ${ }^{36}$ Many in vitro studies confirm the deleterious effect of cigarette smoke (CS) on nasal epithelial cells..$^{37,38}$ Despite these experimental studies, in vivo data on the role of smoking in COPD-associated rhinosinusitis are scarce. Only COPD smokers (but not the entire COPD group) were shown to have reduced mucociliary clearance and increased concentration of 8-isoprostane (a marker of oxidative stress) in nasal lavage when compared to healthy nonsmoking controls. However, no relation to smoking history and current smoking status were found for the severity of symptoms and intensity of mucosal changes..$^{39}$

CRS symptoms significantly impair COPD patients' quality of life, which is usually assessed by dedicated questionnaires (Sino-Nasal Outcome Test [SNOT]-20, SNOT-22, or Sino-Nasal Assessment Questionnaire [SNAQ]-11). ${ }^{31-33,39}$ However CRS symptoms do not impact the disease-specific quality of life, as scored by the use of St George's Respiratory Questionnaire, suggesting that symptoms from the lower and upper respiratory tract influence the quality of life in an independent manner. ${ }^{31,39}$ The most frequently reported symptom is rhinorrhea. ${ }^{31}$ Mucosal abnormalities were reported in endoscopy ${ }^{31,39}$ and $\mathrm{CT} .{ }^{33}$ The symptoms were more intensive, and $\mathrm{CT}$ changes were more frequent in patients with more severe obstruction (grade III and IV), ${ }^{33}$ but this regularity was not confirmed by other authors. ${ }^{39}$ In concordance with the "common airway" concept, the most important would be to show the identity of inflammation in the lower and upper airways. Piotrowska et $\mathrm{l}^{39}$ have not found any differences in the number or percentage of neutrophils, nor differences in the concentration of LTB4 - an eicosanoid related to neutrophilic inflammation - in nasal lavages between COPD and controls. This is contrary to other authors, who found neutrophilic response in the nasal mucosa of stable COPD patients. Hurst et $\mathrm{al}^{40}$ found elevated IL- 8 concentrations in the nasal lavage of COPD patients, and a positive correlation with sputum IL-8. Interestingly, Hens et $\mathrm{al}^{32}$ reported elevated concentrations of eotaxin (an eosinophilic marker), granulocyte colony-stimulating factor and interferon- $\gamma$ in the nasal lavage of COPD patients; moreover, the very same cytokines were found to be elevated in lavages of patients with asthma. Vachier et al ${ }^{41}$ reported higher numbers of $\mathrm{CD} 8^{+}$ and neutrophils in the nasal biopsies of COPD patients. This is the only study so far, with the use of nasal biopsy, to prove the typical signs of COPD inflammation in the nose. No relation to systemic inflammation, defined as elevated serum C-reactive protein concentration, was found. ${ }^{39,40}$

\section{Skin in COPD}

A typical "smokers' face" is characterized by prominent wrinkles, gauntness of facial features, gray appearance of the skin, and a swollen complexion. The association between smoking habit, its intensity, and skin wrinkling was documented many years ago. ${ }^{42}$ Skin wrinkling supposedly reflects accelerated skin aging. CS induces low-grade skin inflammation mediated by reactive oxygen species, which leads to alterations in extracellular matrix turnover. Collagen I and collagen III content in smokers' skin is decreased, which may result from decreased collagen biosynthesis and/or increased degradation. Increased expression of matrix metalloproteinases ([MMP]-1, MMP-2, MMP-3, MMP-7, and MMP-8) and decreased expression of tissue inhibitor of metalloproteinases- 1 have been reported. ${ }^{43-47}$ The skin inflammation induced by smoking may resemble that related to chronic exposure to solar ultraviolet radiation also referred to as photodamage or photoaging. This type of 
damage is associated with skin infiltration with mast cells, macrophages, $\mathrm{CD}^{+}{ }^{+} \mathrm{CD} 45 \mathrm{RO}^{+} \mathrm{T}$-cells, and $\mathrm{CD} \mathrm{a}^{+}$dendritic cells. ${ }^{4-50}$ It was shown, that smoking accelerates skin photoaging, whereas smoking cessation may slow down this process. $^{51}$

The skin of COPD patients also shows signs of accelerated aging, but only in those parts related to the smoking habit. Patel et $\mathrm{al}^{52}$ were the first to prove the susceptibility of smokers with facial wrinkling to COPD. According to these authors, facial wrinkling was not only related to COPD risk ( $\mathrm{OR}=5.0$ ), but its intensity also correlated with the extent of emphysema on CT scans. Other authors have shown that COPD patients have increased skin elastin degradation when compared to smoking-matched control subjects. It was more pronounced in the areas exposed to solar radiation when compared to areas protected from the sun. Of much interest, the intensity of elastin degradation in skin biopsies was correlated with emphysema severity, as assessed by chest CT, and it was shown to be related to messenger RNA expression of MMP-2 and MMP-9. ${ }^{53}$ This finding is aligned with the results of another group of authors, who found an association between elastin fiber abnormalities in the reticular dermis and lung function impairment of an obstructive pattern. ${ }^{54}$ However, skin fibroblasts do not show the same "senescent" as the emphysema-derived pulmonary fibroblast phenotype. ${ }^{55}$

Advanced glycation end products (AGE) are generated by the glycation and oxidation of proteins. AGE accumulate in the tissues and thus may impair the function of different organs. Moreover, when attached to cellular receptors (RAGE), they induce a cascade of events leading to the activation of nuclear factor kappa $B$, which result in the generation of proinflammatory cytokines. AGE and RAGE have been associated with the pathogenesis of many diseases with underlying systemic inflammation, such as diabetes, heart insufficiency, chronic kidney disease and, recently, COPD. ${ }^{56-58}$ Serum AGE and cellular RAGE expression were both elevated in COPD, ${ }^{59}$ and sRAGE, a circulating soluble decoy receptor, was shown to be decreased in COPD, which was inversely correlated with the degree of emphysema. ${ }^{60}$ The skin of COPD patients accumulate AGE, which can be detected by skin autofluorescence. ${ }^{61,62}$ In none of these studies does skin autofluorescence intensity correlate with COPD severity.

\section{Eyes in COPD}

Hypoxia and vascular mediators may be involved in the etiology of some eye disorders. A constant supply of oxygen is crucial to maintain adequate organ function - in particular, in tissues with high energy demand, such as the retina. Thus, it does not come as a surprise that even small alterations in retinal oxygen tension may lead to tissue hypoxia and neuronal death. ${ }^{63}$ New instruments allow for the noninvasive measurement of retinal oxygen saturation in humans. ${ }^{63}$ Celik et $\mathrm{al}^{64}$ evaluated the hemodynamic changes in the extraocular orbital vessels of COPD using color Doppler ultrasonography and showed that severe (stage 3 ) COPD is associated with impaired retrobulbar hemodynamics.

Glaucoma and cataract may be assigned to side effects of COPD treatment. Topical and systemic corticosteroids are well known to raise intraocular pressure, while the effect of inhaled corticosteroids on the risk of glaucoma remains uncertain. In a large cohort of elderly patients treated for airways disease, neither current nor continuous use of high-dose inhaled corticosteroids resulted in an increased risk of glaucoma or raised intraocular pressure requiring treatment. ${ }^{65} \mathrm{COPD}$, like glaucoma and cataract, is a common disease in the elderly. In those individuals above the age of 70 years, glaucoma prevalence is close to $4 \%{ }^{66}$ A population-based cohort study with nested casecontrol analysis using the United Kingdom General Practice Research Database did not find an association between glaucoma and obstructive airway diseases. ${ }^{67}$ Quite the contrary, Soriano et $\mathrm{al}^{68}$ in a large cohort of COPD patients (number $[n]=2,699$ ) from the same database, found that COPD compared to non-COPD patients are at higher risk of glaucoma within the first year after COPD diagnosis (risk ratio $[\mathrm{RR}]=1.3$ ). Of note, $2 \%$ of COPD patients had a record of their cataracts, but this rate was not different than that of the non-COPD cohort. ${ }^{68}$

It was also shown that individuals with neovascular age-related macular degeneration are significantly more likely to have emphysema and COPD. Also, hypertension, hypercholesterolemia, atherosclerosis, arthritis, coronary heart disease, cataract, glaucoma, and myopia were found to be more frequent in these patients. ${ }^{69}$ Independently of smoking, a history of emphysema, respiratory symptoms, and lung function impairment are modestly, but inconsistently, associated with the incidence and progression of age-related macular degeneration. ${ }^{70}$

Significant decreases in endothelial cell density, hexagonality, corneal thickness, and a significant increase in the endothelial cell size coefficient of variation were found in COPD patients. They also presented with a significant decrease in serum antioxidant enzyme paraoxonase (PON)1 activity, but not in PON1 concentration. Serum PON1 activity 
showed a significant direct association with endothelial cell density and an inverse association with corneal thickness. Therefore, the authors suggest that PON1 may be involved in the pathophysiology of corneal endothelial alterations in patients with COPD. ${ }^{71}$

\section{Endocrinological disorders in COPD patients}

Diabetes mellitus type 2, osteoporosis, and metabolic syndrome are well-known endocrinological comorbidities in COPD. ${ }^{9}$ In some patients, COPD is associated with muscle wasting and weakness, and thus many reports are focused on anabolic hormones, thyroid function, and the adrenal glands. ${ }^{72}$ A range of mechanisms, including systemic inflammation, neurohormones, blood gas disturbances, and glucocorticoid administration, contribute to the anabolic/ catabolic imbalance and impaired whole-body metabolism in COPD. ${ }^{73-76}$

Some studies show that thyroid diseases are more frequent among patients with COPD. In a big population-based study performed in the city of Madrid, Spain, it was shown that the prevalence of a thyroid disease was higher in COPD patients $(14.21 \%)$ than the expected standardized prevalence of chronic diseases (11.06\%). ${ }^{21} \mathrm{~A}$ strong positive correlation between the total $\mathrm{T} 3 /$ total $\mathrm{T} 4$ ratio and $\mathrm{PaO}_{2}$ in patients with respiratory insufficiency was described. ${ }^{75}$ Increased free (F)T3 concentrations have been reported in stable COPD, with a positive association to $\mathrm{PaCO}_{2},{ }^{76}$ while others reported lower total T3, FT3, and totalT3/totalT4 ratios in patients with severe hypoxemia. ${ }^{77}$ Mancini et al ${ }^{78}$ evaluated thyroid hormones and antioxidant defense - the lipophilic coenzyme Q10 $\left(\mathrm{CoQ}_{10}\right)$ and total antioxidant capacity- in COPD patients to reveal the presence of a low-T3 syndrome in COPD and to investigate the correlation between thyroid hormones, lung function parameters, and antioxidants. They found significantly lower FT3 and FT4 levels and significantly higher thyroid-stimulating hormone levels in COPD patients versus controls. ${ }^{78}$ Their research seems to indicate an increased oxidative stress in low FT3 COPD and a role of FT3 in modulating antioxidant defense. These data might suggest the need for thyroid replacement therapy in a low-T3 syndrome in COPD patients. ${ }^{78}$

Many studies have shown that middle-aged and elderly COPD patients may develop hypogonadism. ${ }^{79-82}$ The prevalence of hypogonadism in men with COPD can range from $22 \%-69 \%$, and it has been associated with several other systemic manifestations including osteoporosis, depression, and muscle weakness. ${ }^{79}$ However, the relationship between hypogonadism and COPD still remains poorly understood. The current literature is, at best, circumstantial. ${ }^{79,82}$ A sex hormone deficiency in men can be correlated with COPD stages and disease progression. ${ }^{83}$ There are only a few long-term trials evaluating the effects of androgens on the parameters of respiratory function in patients with COPD. ${ }^{79,83,84}$ Changes of testosterone levels in patients with COPD correlate with $\mathrm{FEV}_{1}$, hypoxemia, and hypercapnia levels. ${ }^{79,84}$ Glucocorticosteroids exacerbate androgen deficiency in patients with COPD, and the use of hormone replacement therapy with testosterone in these patients is justified. Androgens, especially the testosterone depot, can be effectively used in the treatment and rehabilitation of patients with COPD. ${ }^{85}$ Testosterone replacement therapy may result in modest improvements in fat-free mass and limb muscle strength, but its therapeutic efficacy in COPD patients still remains controversial. $^{79}$

Adrenal insufficiency (AI) is an uncommon but lifethreatening disorder if it progresses to adrenal crisis. In some COPD patients, previous glucocorticosteroid intake may be responsible for the occurrence of AI. The annual incidence of $\mathrm{AI}$ in Taiwan has continuously increased in recent years, and elderly patients accounted for the majority of the increase. The most common comorbidity for AI was pneumonia $(6.4 \%)$, followed by urinary tract infection $(6.4 \%)$, diabetes mellitus (6.2\%), electrolyte imbalance (4.8\%), and COPD $(4.5 \%){ }^{85}$

It has been suggested that COPD patients have abnormal circadian rhythms, and they suffer from cognitive function, $\operatorname{mood} /$ anxiety, and sleep abnormalities because of disturbances in corticosterone release - an adrenal steroid that plays a considerable role in stress and anti-inflammatory responses. $^{74}$

\section{Gastroesophageal reflux disease}

The frequent coexistence of GERD among patients with COPD has been described before. ${ }^{86}$ Treatment with bronchodilators (such as theophylline or beta-agonists) has been considered as causative factors; however, the literature data on the possible causative links are ambiguous. ${ }^{87}$ Obstructive sleep apnea, a frequent comorbidity of COPD, may also exacerbate diaphragm and lower esophageal sphincter dysfunction and increase the propensity for and severity of GERD ${ }^{88}$ It may not be excluded that mere COPD symptoms (like frequent and severe cough) increase the intrathoracic pressure, thus contributing to reflux occurrence; however, the data confirming this hypothesis are lacking. GERD was present in almost one-third of elderly COPD patients and 
it shows female predominance. ${ }^{89}$ It was shown to be associated with a higher risk of cardiovascular comorbidity. ${ }^{90}$ It significantly impacts the severity of symptoms ${ }^{89,90}$ and quality of life ${ }^{89,90}$ Coexistent GERD significantly increases health care costs. ${ }^{90}$ GERD symptoms were also shown to be associated with a higher risk of exacerbations $(\mathrm{RR}=6.5) .{ }^{91}$ The presence of GERD symptoms does not influence the inflammatory response in the airways; ${ }^{92}$ therefore, other mechanisms by which GERD affects COPD exacerbations should be sought. The increase in bronchial hyperresponsiveness in patients with GERD could explain the impact on COPD symptoms and the increased risk of exacerbations; however, it was shown that the treatment of patients with severe hyperresponsiveness (both asthma and COPD) and coexisting GERD with a high-dose proton pump inhibitor for a period of 3 months did not alleviate respiratory symptoms, nor did it decrease the threshold of bronchial hyperreactivity. ${ }^{92}$

\section{Other underrecognized manifestations}

Little was known about the relationships between COPD and liver diseases until population-based surveys demonstrated that COPD patients have a substantially elevated risk of gallbladder disease, pancreatic disease, and asymptomatic elevations of hepatic transaminases unrelated to right heart failure. ${ }^{93}$ The same survey and retrospective study revealed that renal complications of COPD are common, especially among patients with hypoxemia and hypercarbia. Renalendocrine mechanisms, tissue hypoxia, and vascular rigidity play roles in the pathophysiology, but a causal relationship is not precisely recognized. ${ }^{93}$

\section{Conclusion}

Not all is known about COPD comorbidities. Many symptoms may be overlooked or belittled by physicians. Sometimes it is difficult to distinguish between COPD complications, drug-related symptoms and treatment complications, and real comorbidities. Quality of life is one of the main indications of well-being and it may be severely impaired by still underrecognized manifestations. Some of these comorbidities may even be life threatening. Common pathways may be involved in the pathogenesis of COPD and its comorbidities. Therefore, better recognition of these complicated relationships between different diseases may be important for the knowledge on the COPD itself. Improved management of these conditions may result in improved quality of life and health care-related cost reduction.

\section{Acknowledgment}

The authors are supported by the Healthy Ageing Research Centre project (REGPOT-2012-2013-1, 7FP).

\section{Disclosure}

The authors report no conflicts of interest in this work.

\section{References}

1. Agusti A, Sobradillo P, Celli B. Addressing the complexity of chronic obstructive pulmonary disease: from phenotypes and biomarkers to scale-free networks, systems biology, and P4 medicine. Am J Respir Crit Care Med. 2011;183(9):1129-1137.

2. Barnes PJ, Celli BR. Systemic manifestations and comorbidities of COPD. Eur Respir J. 2009;33(5):1165-1185.

3. Boros PW, Lubiński W. Health state and the quality of life in patients with chronic obstructive pulmonary disease in Poland: a study using the EuroQoL-5D questionnaire. Pol Arch Med Wewn. 2012;122(3):73-81.

4. Antonelli Incalzi R, Fuso L, De Rosa M, et al. Co-morbidity contributes to predict mortality of patients with chronic obstructive pulmonary disease. Eur Respir J. 1997;10(12):2794-2800.

5. Glynn LG, Valderas JM, Healy P, et al. The prevalence of multimorbidity in primary care and its effect on health care utilization and cost. Fam Pract. 2011;28(5):516-523.

6. Bustacchini S, Chiatti C, Furneri G, Lattanzio F, Mantovani LG. The economic burden of chronic obstructive pulmonary disease in the elderly: results from a systematic review of the literature. Curr Opin Pulm Med. 2011;17 Suppl 1:S35-S41.

7. McDaid O, Hanly MJ, Richardson K, Kee F, Kenny RA, Savva GM. The effect of multiple chronic conditions on self-rated health, disability and quality of life among the older populations of Northern Ireland and the Republic of Ireland: a comparison of two nationally representative cross-sectional surveys. BMJ Open. 2013;3(6). pii: e002571.

8. Frei A, Muggensturm P, Putcha N, et al. Five comorbidities reflected the health status in patients with chronic obstructive pulmonary disease: the newly developed COMCOLD index. J Clin Epidemiol. 2014; 67(8):904-911.

9. Global Initiative for Chronic Obstructive Lung Disease (GOLD) [homepage on the Internet]. Global strategy for the diagnosis, management, and prevention of COPD. Global Initiative for Chronic Obstructive Lung Disease (GOLD); 2015. Leuven (Belgium), Marburg (Germany). Available from: http://web.archive.org/web/20150227051533/http:// www.goldcopd.org. Accessed February 27, 2015.

10. Ito K, Barnes PJ. COPD as a disease of accelerated lung aging. Chest. 2009;135(1):173-180.

11. Amsellem V, Gary-Bobo G, Marcos E, et al. Telomere dysfunction causes sustained inflammation in chronic obstructive pulmonary disease. Am J Respir Crit Care Med. 2011;184(12):1358-1366.

12. Ito K, Colley T, Mercado N. Geroprotectors as a novel therapeutic strategy for COPD, an accelerating aging disease. Int J Chron Obstruct Pulmon Dis. 2012;7:641-652.

13. Barnes PJ. Mechanisms of development of multimorbidity in the elderly. Eur Respir J. 2015;45(3):790-806.

14. Papaioannou AI, Mazioti A, Kiropoulos T, et al. Systemic and airway inflammation and the presence of emphysema in patients with COPD. Respir Med. 2010;104(2):275-282.

15. Salanitro AH, Ritchie CS, Hovater M, et al. Inflammatory biomarkers as predictors of hospitalization and death in community-dwelling older adults. Arch Gerontol Geriatr. 2012;54(3):e387-e391.

16. Moy ML, Teylan M, Danilack VA, Gagnon DR, Garshick E. An index of daily step count and systemic inflammation predicts clinical outcomes in chronic obstructive pulmonary disease. Ann Am Thorac Soc. 2014; 11(2):149-157.

17. Mannino DM, Valvi D, Mullerova H, Tal-Singer R. Fibrinogen, COPD and mortality in a nationally representative U.S. cohort. COPD. 2012; 9(4):359-366. 
18. Vanfleteren LE, Spruit MA, Groenen M, et al. Clusters of comorbidities based on validated objective measurements and systemic inflammation in patients with chronic obstructive pulmonary disease. Am J Respir Crit Care Med. 2013;187(7):728-735.

19. Fu JJ, McDonald VM, Gibson PG, Simpson JL. Systemic inflammation in older adults with asthma-COPD overlap syndrome. Allergy Asthma Immunol Res. 2014;6(4):316-324.

20. Garcia-Aymerich J, Gómez FP, Benet M, et al; PAC-COPD Study Group. Identification and prospective validation of clinically relevan chronic obstructive pulmonary disease (COPD) subtypes. Thorax. 2011 $66(5): 430-437$.

21. García-Olmos L, Salvador CH, Alberquilla Á, et al. Comorbidity patterns in patients with chronic diseases in general practice. PLoS One. 2012;7(2):e32141.

22. Fokkens WJ, Lund VJ, Mullol J, et al. EPOS 2012: European position paper on rhinosinusitis and nasal polyps 2012. A summary for otorhinolaryngologists. Rhinology. 2012;50(1):1-12.

23. Halawi AM, Smith SS, Chandra RK. Chronic rhinosinusitis: epidemiology and cost. Allergy Asthma Proc. 2013;34(4):328-334.

24. Tomassen P, Newson RB, Hoffmans R, et al. Reliability of EP3OS symptom criteria and nasal endoscopy in the assessment of chronic rhinosinusitis - a GA² LEN study. Allergy. 2011;66(4):556-561.

25. Hastan D, Fokkens WJ, Bachert C, et al. Chronic rhinosinusitis in European underestimated disease. A GA ${ }^{2}$ LEN study. Allergy. 2011;66(9): 1216-1223.

26. Chandra RK, Lin D, Tan B, et al. Chronic rhinosinusitis in the setting of other chronic inflammatory diseases. Am J Otolaryngol. 2011; 32(5):388-391.

27. Leynaert B, Neukirch F, Demoly P, Bousquet J. Epidemiologic evidence for asthma and rhinitis comorbidity. J Allergy Clin Immunol. 2000; 106(5 Suppl):S201-S205.

28. Nutku E, Toda M, Hamid QA. Rhinitis, nasal polyposis and asthma: pathological aspects. In: Wallaert $\mathrm{B}$, Chanez $\mathrm{P}$, Godard P, editors. The Nose and Lung Diseases. European Respiratory Monograph. 2001;6: 115-142.

29. Chen Y, Dales R, Lin M. The epidemiology of chronic rhinosinusitis in Canadians. Laryngoscope. 2003;113(7):1199-1205.

30. Roberts NJ, Lloyd-Owen SJ, Rapado F, et al. Relationship between chronic nasal and respiratory symptoms in patients with COPD. Respir Med. 2003;97(8):909-914.

31. Hurst JR, Wilkinson TM, Donaldson GC, Wedzicha JA. Upper airway symptoms and quality of life in chronic obstructive pulmonary disease (COPD). Respir Med. 2004;98(8):767-770.

32. Hens G, Vanaudenaerde BM, Bullens DM, et al. Sinonasal pathology in nonallergic asthma and COPD: 'united airway disease' beyond the scope of allergy. Allergy. 2008;63(3):261-267.

33. Kelemence A, Abadoglu O, Gumus C, Berk S, Epozturk K, Akkurt I. The frequency of chronic rhinosinusitis/nasal polyp in COPD and its effect on the severity of COPD. COPD. 2011;8(1):8-12.

34. Nicola ML, Carvalho HB, Yoshida CT, et al. Young "healthy" smokers have functional and inflammatory changes in the nasal and the lower airways. Chest. 2014;145(5):998-1005.

35. Lachanas VA, Tsea M, Tsiouvaka S, Exarchos ST, Skoulakis CE, Bizakis JG. The effect of active cigarette smoking on Sino-Nasal Outcome Test in 127 subjects without rhinologic disease. A prospective study. Clin Otolaryngol. 2015;40(1):56-59.

36. Uhliarova B, Adamkov M, Svec M, Calkovska A. The effect of smoking on CT score, bacterial colonization and distribution of inflammatory cells in the upper airways of patients with chronic rhinosinusitis. Inhal Toxicol. 2014;26(7):419-425.

37. Pace E, Ferraro M, Di Vincenzo S, et al. Oxidative stress and innate immunity responses in cigarette smoke stimulated nasal epithelial cells. Toxicol In Vitro. 2014;28(2):292-299.

38. Virgin FW, Azbell C, Schuster D, et al. Exposure to cigarette smoke condensate reduces calcium activated chloride channel transport in primary sinonasal epithelial cultures. Laryngoscope. 2010;120(7): 1465-1469.
39. Piotrowska VM, Piotrowski WJ, Kurmanowska Z, Marczak J, Górski P, Antczak A. Rhinosinusitis in COPD: symptoms, mucosal changes, nasal lavage cells and eicosanoids. Int J Chron Obstruct Pulmon Dis. 2010;5: $107-117$.

40. Hurst JR, Wilkinson TM, Perera WR, Donaldson GC, Wedzicha JA. Relationships among bacteria, upper airway, lower airway, and systemic inflammation in COPD. Chest. 2005;127(4):1219-1226.

41. Vachier I, Vignola AM, Chiappara G, et al. Inflammatory features of nasal mucosa in smokers with and without COPD. Thorax. 2004; 59(4):303-307.

42. Daniell HW. Smoker's wrinkles. A study in the epidemiology of “crow's feet”. Ann Intern Med. 1971;75(6):873-880.

43. Yin L, Morita A, Tsuji T. Alterations of extracellular matrix induced by tobacco smoke extract. Arch Dermatol Res. 2000;292(4):188-194.

44. Lahmann C, Bergemann J, Harrison G, Young AR. Matrix metalloproteinase-1 and skin ageing in smokers. Lancet. 2001;357(9260): 935-936.

45. Knuutinen A, Kokkonen N, Risteli J, et al. Smoking affects collagen synthesis and extracellular matrix turnover in human skin. $\mathrm{Br} J \mathrm{Der}$ matol. 2002;146(4):588-594.

46. Just M, Ribera M, Monsó E, Lorenzo JC, Ferrándiz C. Effect of smoking on skin elastic fibres: morphometric and immunohistochemical analysis. Br J Dermatol. 2007;156(1):85-91.

47. Ortiz A, Grando SA. Smoking and the skin. Int J Dermatol. 2012;51(3): 250-262.

48. Bosset S, Bonnet-Duquennoy M, Barré P, et al. Photoageing shows histological features of chronic skin inflammation without clinical and molecular abnormalities. Br J Dermatol. 2003;149(4):826-835.

49. Iddamalgoda A, Le QT, Ito K, Tanaka K, Kojima H, Kido H. Mast cell tryptase and photoaging: possible involvement in the degradation of extra cellular matrix and basement membrane proteins. Arch Dermatol Res. 2008;300 Supp1 1:S69-S76.

50. Kaukinen A, Fitzgibbon A, Oikarinen A, Hinkkanen L, Viinikanoja M, Harvima IT. Increased numbers of tryptase-positive mast cells in the healthy and sun-protected skin of tobacco smokers. Dermatology. 2014;229(4):353-358.

51. Chung JH, Lee SH, Youn CS, et al. Cutaneous photodamage in Koreans: influence of sex, sun exposure, smoking, and skin color. Arch Dermatol. 2001;137(8):1043-1051.

52. Patel BD, Loo WJ, Tasker AD, et al. Smoking related COPD and facial wrinkling: is there a common susceptibility? Thorax. 2006;61(7): 568-571.

53. Maclay JD, McAllister DA, Rabinovich R, et al. Systemic elastin degradation in chronic obstructive pulmonary disease. Thorax. 2012; 67(7):606-612.

54. Just M, Monsó E, Ribera M, Lorenzo JC, Morera J, Ferrandiz C. Relationships between lung function, smoking and morphology of dermal elastic fibres. Exp Dermatol. 2005;14(10):744-751.

55. Müller KC, Paasch K, Feindt B, et al. In contrast to lung fibroblasts no signs of senescence in skin fibroblasts of patients with emphysema. Exp Gerontol. 2008;43(7):623-628.

56. Buckley ST, Ehrhardt C. The receptor for advanced glycation end products (RAGE) and the lung. J Biomed Biotechnol. 2010;2010:917108.

57. Lee EJ, Park JH. Receptor for advanced glycation endproducts (RAGE), its ligands, and soluble RAGE: potential biomarkers for diagnosis and therapeutic targets for human renal diseases. Genomics Inform. 2013; 11(4):224-229.

58. Morbini P, Villa C, Campo I, Zorzetto M, Inghilleri S, Luisetti M. The receptor for advanced glycation end products and its ligands: a new inflammatory pathway in lung disease? Mod Pathol. 2006;19(11): 1437-1445.

59. Wu L, Ma L, Nicholson LF, Black PN. Advanced glycation end products and its receptor (RAGE) are increased in patients with COPD. Respir Med. 2011;105(3):329-336.

60. Smith DJ, Yerkovich ST, Towers MA, Carroll ML, Thomas R, Upham JW. Reduced soluble receptor for advanced glycation endproducts in COPD. Eur Respir J. 2011;37(3):516-522. 
61. Gopal P, Reynaert NL, Scheijen JL, et al. Plasma advanced glycation end-products and skin autofluorescence are increased in COPD. Eur Respir J. 2014;43(2):430-438.

62. Hoonhorst SJ, Lo Tam Loi AT, Hartman JE, et al. Advanced glycation end products in the skin are enhanced in COPD. Metabolism. 2014;63(9):1149-1156.

63. Palkovits S, Lasta M, Told R, et al. Retinal oxygen metabolism during normoxia and hyperoxia in healthy subjects. Invest Ophthalmol Vis Sci. 2014;55(8):4707-4713.

64. Celik C, Tokgöz O, Serifoğlu L, Tor M, Alpay A, Erdem Z. Color Doppler evaluation of the retrobulbar hemodynamic changes in chronic obstructive pulmonary disease: COPD and retrobulbar hemodynamic changes. Ultrason Imaging. 2014;36(3):177-186.

65. Gonzalez AV, Li G, Suissa S, Ernst P. Risk of glaucoma in elderly patients treated with inhaled corticosteroids for chronic airflow obstruction. Pulm Pharmacol Ther. 2010;23(2):65-70.

66. Nesher R; Israel Glaucoma Screening Group. Prevalence of increased intraocular pressure and optic disk cupping: multicenter glaucoma screening in Israel during the 2009 and 2010 World Glaucoma Weeks. Isr Med Assoc J. 2014;16(8):483-486.

67. Huerta C, García Rodríguez LA, Möller CS, Arellano FM. The risk of obstructive airways disease in a glaucoma population. Pharmacoepidemiol Drug Saf. 2001;10(2):157-163.

68. Soriano JB, Visick GT, Muellerova H, Payvandi N, Hansell AL. Patterns of comorbidities in newly diagnosed COPD and asthma in primary care. Chest. 2005;128(4):2099-2107.

69. Zlateva GP, Javitt JC, Shah SN, Zhou Z, Murphy JG. Comparison of comorbid conditions between neovascular age-related macular degeneration patients and a control cohort in the medicare population. Retina. 2007;27(9):1292-1299.

70. Klein R, Knudtson MD, Klein BE. Pulmonary disease and age-related macular degeneration: the Beaver Dam Eye Study. Arch Ophthalmol. 2008;126(6):840-846.

71. Soler N, García-Heredia A, Marsillach J, et al. Paraoxonase-1 is associated with corneal endothelial cell alterations in patients with chronic obstructive pulmonary disease. Invest Ophthalmol Vis Sci. 2013;54(8): $5852-5858$

72. Doehner W, Haeusler KG, Endres M, Anker SD, MacNee W, Lainscak M. Neurological and endocrinological disorders: orphans in chronic obstructive pulmonary disease. Respir Med.2011;105 Suppl 1: S12-S19.

73. Creutzberg EC, Casaburi R. Endocrinological disturbances in chronic obstructive pulmonary disease. Eur Respir J Suppl. 2003;46: $76 \mathrm{~s}-80 \mathrm{~s}$.

74. Sundar IK, Yao H, Huang Y, et al. Serotonin and corticosterone rhythms in mice exposed to cigarette smoke and in patients with COPD: implication for COPD-associated neuropathogenesis. PLoS One. 2014;9(2):e87999.

75. Dimopoulou I, Ilias I, Mastorakos G, Mantzos E, Roussos C, Koutras DA. Effects of severity of chronic obstructive pulmonary disease on thyroid function. Metabolism. 2001;50(12):1397-1401.

76. Okutan O, Kartaloglu Z, Onde ME, Bozkanat E, Kunter E. Pulmonary function tests and thyroid hormone concentrations in patients with chronic obstructive pulmonary disease. Med Princ Pract. 2004;13(3): 126-128.

77. Karadag F, Ozcan H, Karul AB, Yilmaz M, Cildag O. Correlates of nonthyroidal illness syndrome in chronic obstructive pulmonary disease. Respir Med. 2007;101(7):1439-1446.

78. Mancini A, Corbo GM, Gaballo A, et al. Relationship between plasma antioxidants and thyroid hormones in chronic obstructive pulmonary disease. Exp Clin Endocrinol Diabetes. 2012;120(10):623-628.

79. Balasubramanian V, Naing S. Hypogonadism in chronic obstructive pulmonary disease: incidence and effects. Curr Opin Pulm Med. 2012;18(2): 112-117.

80. Karakou E, Glynos C, Samara KD, Msaouel P, Koutsilieris M, Vassilakopoulos T. Profile of endocrinological derangements affecting PSA values in patients with COPD. In Vivo. 2013;27(5):641-649.
81. Corbo GM, Di Marco Berardino A, Mancini A, et al. Serum level of testosterone, dihydrotestosterone and IGF-1 during an acute exacerbation of COPD and their relationships with inflammatory and prognostic indices: a pilot study. Minerva Med. 2014;105(4):289-294.

82. Laghi F, Antonescu-Turcu A, Collins E, et al. Hypogonadism in men with chronic obstructive pulmonary disease: prevalence and quality of life. Am J Respir Crit Care Med. 2005;171(7):728-733.

83. Mousavi SA, Kouchari MR, Samdani-Fard SH, Gilvaee ZN, Arabi M. Relationship between serum levels of testosterone and the severity of chronic obstructive pulmonary disease. Tanaffos. 2012;11(3): 32-35.

84. Vertkin AL, Morgunov LIu, Shakhmanaev KhA. [Hypogonadism and chronic obstructive pulmonary disease]. Urologiia. 2013;(5):116-118; 120-122. Russian

85. Chen YC, Lin YH, Chen SH, et al. Epidemiology of adrenal insufficiency: a nationwide study of hospitalizations in Taiwan from 1996 to 2008. J Chin Med Assoc. 2013;76(3):140-145.

86. Martinez CH, Okajima Y, Murray S, et al; COPDGene Investigators. Impact of self-reported gastroesophageal reflux disease in subjects from COPDGene cohort. Respir Res. 2014;15:62.

87. Harding SM, Guzzo MR, Richter JE. 24-h esophageal $\mathrm{pH}$ testing in asthmatics: respiratory symptom correlation with esophageal acid events. Chest. 1999;115(3):654-659.

88. Emilsson OI, Janson C, Benediktsdóttir B, Júlíusson S, Gíslason T. Nocturnal gastroesophageal reflux, lung function and symptoms of obstructive sleep apnea: Results from an epidemiological survey. Respir Med. 2012;106(3):459-466.

89. Miyazaki M, Nakamura H, Chubachi S, et al; Keio COPD Comorbidity Research (K-CCR) Group. Analysis of comorbid factors that increase the COPD assessment test scores. Respir Res. 2014;15:13.

90. Ajmera M, Raval AD, Shen C, Sambamoorthi U. Explaining the increased health care expenditures associated with gastroesophageal reflux disease among elderly Medicare beneficiaries with chronic obstructive pulmonary disease: a cost-decomposition analysis. Int J Chron Obstruct Pulmon Dis. 2014;9:339-348.

91. Terada K, Muro S, Sato S, et al. Impact of gastro-oesophageal reflux disease symptoms on COPD exacerbation. Thorax. 2008;63(11): 951-955.

92. Boeree MJ, Peters FT, Postma DS, Kleibeuker JH. No effects of high-dose omeprazole in patients with severe airway hyperresponsiveness and (a)symptomatic gastro-oesophageal reflux. Eur Respir J. 1998;11(5):1070-1074.

93. Mapel D. Renal and hepatobiliary dysfunction in chronic obstructive pulmonary disease. Curr Opin Pulm Med. 2014;20(2):186-193.

94. Terzano C, Romani S, Paone G, Conti V, Oriolo F. COPD and thyroid dysfunctions. Lung. 2014;192(1):103-109.

95. Divo M, Cote C, de Torres JP, et al; BODE Collaborative Group. Comorbidities and risk of mortality in patients with chronic obstructive pulmonary disease. Am J Respir Crit Care Med. 2012;186(2): $155-161$.

96. Kim J, Lee JH, Kim Y, et al. Association between chronic obstructive pulmonary disease and gastroesophageal reflux disease: a national cross-sectional cohort study. BMC Pulm Med. 2013;13:51.

97. Ferguson GT, Calverley PM, Anderson JA, et al. Prevalence and progression of osteoporosis in patients with COPD: results from the TOwards a Revolution in COPD Health study. Chest. 2009;136(6): 1456-1465.

98. Curkendall SM, DeLuise C, Jones JK, et al. Cardiovascular disease in patients with chronic obstructive pulmonary disease, Saskatchewan Canada cardiovascular disease in COPD patients. Ann Epidemiol. 2006;16(1):63-70.

99. Keller CA, Shepard JW, Chun DS, Vasquez P, Dolan GF. Pulmonary hypertension in chronic obstructive pulmonary disease. Multivariate analysis. Chest. 1986;90(2):185-192.

100. Finkelstein J, Cha E, Scharf SM. Chronic obstructive pulmonary disease as an independent risk factor for cardiovascular morbidity. Int J Chron Obstruct Pulmon Dis. 2009;4:337-349. 
101. Gudmundsson G, Gislason T, Janson C, et al. Depression, anxiety and health status after hospitalisation for COPD: a multicentre study in the Nordic countries. Respir Med. 2006;100(1):87-93.

102. Hanania NA, Müllerova H, Locantore NW, et al; Evaluation of COPD Longitudinally to Identify Predictive Surrogate Endpoints (ECLIPSE) study investigators. Determinants of depression in the ECLIPSE chronic obstructive pulmonary disease cohort. Am J Respir Crit Care Med. 2011;183(5):604-611.
103. Mapel DW, Picchi MA, Hurley JS, et al. Utilization in COPD: patient characteristics and diagnostic evaluation. Chest. 2000;117(5 Suppl 2): 346S-53S.

104. Kühl K, Schürmann W, Rief W. Mental disorders and quality of life in COPD patients and their spouses. Int J Chron Obstruct Pulmon Dis. 2008;3(4):727-736.

International Journal of COPD

\section{Publish your work in this journal}

The International Journal of COPD is an international, peer-reviewed journal of therapeutics and pharmacology focusing on concise rapid reporting of clinical studies and reviews in COPD. Special focus is given to the pathophysiological processes underlying the disease, intervention programs, patient focused education, and self management protocols.

\section{Dovepress}

This journal is indexed on PubMed Central, MedLine and CAS. The manuscript management system is completely online and includes a very quick and fair peer-review system, which is all easy to use. Visit http://www.dovepress.com/testimonials.php to read real quotes from published authors.

Submit your manuscript here: http://www.dovepress.com/international-journal-of-chronic-obstructive-pulmonary-disease-journal 